\title{
Larva of the greater wax moth, Galleria mellonella, is a suitable alternative host for studying virulence of fish pathogenic Vibrio anguillarum
}

Stuart McMillan ${ }^{1}$, David Verner-Jeffreys ${ }^{2}$, Jason Weeks ${ }^{2,3}$, Brian Austin $^{1}$ and Andrew P. Desbois ${ }^{1 *}$

\begin{abstract}
Background: Microbial diseases cause considerable economic losses in aquaculture and new infection control measures often rely on a better understanding of pathogenicity. However, disease studies performed in fish hosts often require specialist infrastructure (e.g., aquaria), adherence to strict legislation and do not permit high-throughput approaches; these reasons justify the development of alternative hosts. This study aimed to validate the use of larvae of the greater wax moth (Galleria mellonella) to investigate virulence of the important fish pathogen, Vibrio anguillarum.
\end{abstract}

Results: Using 11 wild-type isolates of $V$. anguillarum, these bacteria killed larvae in a dose-dependent manner and replicated inside the haemolymph, but infected larvae were rescued by antibiotic therapy. Crucially, virulence correlated significantly and positively in larva and Atlantic salmon (Salmo salar) infection models. Challenge studies with mutants knocked out for single virulence determinants confirmed conserved roles in larva and fish infections in some cases (pJM1 plasmid, rtxA), but not all (empA, flaA, flaE).

Conclusions: The G. mellonella model is simple, more ethically acceptable than experiments on vertebrates and, crucially, does not necessitate liquid systems, which reduces infrastructure requirements and biohazard risks associated with contaminated water. The G. mellonella model may aid our understanding of microbial pathogens in aquaculture and lead to the timely introduction of new effective remedies for infectious diseases, while adhering to the principles of replacement, reduction and refinement (3Rs) and considerably reducing the number of vertebrates used in such studies.

Keywords: Alternative host, Atlantic salmon, Replacement, reduction and refinement (3Rs), Vibriosis, Wax moth larvae

\section{Background}

Aquaculture plays an increasingly important role in global food production, but microbial diseases continue to cause considerable economic losses to producers and impact negatively on animal welfare [1]. To address microbial disease problems, there is a requirement for deeper understanding of the processes involved during infection, as this will lead to new and improved treatments, vaccinations and management practices. To this end, many studies are performed in vertebrate aquatic hosts such as zebrafish (Danio rerio); however, these

\footnotetext{
* Correspondence: ad54@stir.ac.uk

${ }^{1}$ Marine Biotechnology Research Group, Institute of Aquaculture, School of Natural Sciences, University of Stirling, Stirling, UK

Full list of author information is available at the end of the article
}

experiments require specialist infrastructure such as aquaria and biosecurity measures to ensure the safety of workers and aquatic animal stocks, particularly for zoonotic pathogens [2]. In addition, whole-animal studies often are costly, do not permit high-throughput approaches, and are covered by strict legislation [3, 4]. Furthermore, good practice prescribes that researchers should adhere to the principles of the 3Rs, i.e., the replacement, reduction and refinement of experiments on animals [5]. Thus, there is strong justification to pursue alternative infection models when studying microbial pathogens of farmed fish. Alternative infection models can be used because many innate immune responses are functionally conserved across phyla, and pathogens often 
employ similar mechanisms to exploit different hosts [4]. Still, relatively few studies have described alternative infection models for investigating microbial pathogens of fish, but those available include cell culture [6-8], the amoeba Dictyostelium discoideum [2], the nematode Caenorhabditis elegans [9], the freshwater ciliate Tetrahymena thermophila [10], the crustacean Artemia franciscana [11] and D. rerio larvae [12, 13]. Even so, each model is associated with shortcomings such as the need for timeconsuming training to achieve competence, a requirement for tissue culture or aquarium facilities, the lack of important aspects of immune complexity, or being unsuited to the study of certain pathogen virulence traits.

The larva of the greater wax moth (Galleria mellonella) is one alternative model attracting much attention in part due to the simplicity and reliability of establishing infections in this insect [14]. Moreover, there is functional similarity in the innate immune responses to invasive infection between insects and fish with respect to pathogen recognition, expression of antimicrobial peptides, generation of reactive oxygen species, phagocytosis of invading microbes, and initiation of clotting cascades [15-19]. The larvae are a convenient size for manipulation $(2$ to $3 \mathrm{~cm}$ in length), do not need feeding, require little space or specialist infrastructure, and are inexpensive to purchase [14]. Furthermore, the techniques needed to work with this model are achieved after only limited instruction, and studies on this model are ethically more acceptable than working with vertebrates [14]. Notably, the G. mellonella model presents a low biohazard risk because no liquid systems are required and the larvae are kept in Petri dishes with infected material made safe by autoclaving. In addition, this model has been used successfully to study virulence of various human pathogens and the efficacy of antibiotic therapies [20]. Still, newly proposed alternative models need to be validated for each pathogen to ensure that an infection occurs, virulence correlates with that observed in the native host, and that conserved virulence mechanisms are involved during infection.

Therefore, the aim of this present study was to assess the suitability of G. mellonella as an alternative host to investigate the virulence and pathogenicity of fish pathogens. Vibrio anguillarum was selected as the pathogen of interest to validate this alternative infection model because a range of strains and genetic resources are available and much is known of its key virulence mechanisms [21-23]. Moreover, this well-studied Gram-negative bacterium infects many farmed species and continues to cause considerable economic losses worldwide [21, 22, 24].

\section{Methods}

\section{Reagents and culture media}

All chemicals and reagents were purchased from SigmaAldrich Ltd (Poole, UK) unless stated. All solutions were made with distilled water except that MilliQ (Millipore Ltd, Watford, UK) was used for molecular biology. Phosphate-buffered saline (PBS) was made up according to Desbois and Coote [20]. Bacteria were cultured routinely on $1.5 \%(\mathrm{w} / \mathrm{v}) \mathrm{NaCl}$-supplemented tryptone soya agar (TSA; Oxoid, Basingstoke, UK) and broth (TSB; Oxoid) or $1 \%(\mathrm{w} / \mathrm{v}) \mathrm{NaCl}$-supplemented LB agar and broth (Fisher Scientific, Fair Lawn, NJ, USA), whereas Mueller-Hinton broth (MHB; Oxoid) supplemented with $2 \%(\mathrm{w} / \mathrm{v}) \mathrm{NaCl}$ was used for minimum inhibitory concentration (MIC) determinations. Where required, medium was supplemented with $5 \mu \mathrm{g} / \mathrm{mL}$ chloramphenicol (CHL), $80 \mu \mathrm{g} / \mathrm{mL}$ kanamycin (KAN), $2 \mu \mathrm{g} / \mathrm{mL}$ penicillin G (PEN) or $200 \mu \mathrm{g} / \mathrm{mL}$ streptomycin (STR). Water, PBS and culture media were sterilised by autoclaving at $121^{\circ} \mathrm{C}$ for $15 \mathrm{~min}$.

\section{Bacteria}

$V$. anguillarum strains (Table 1) were kept routinely at $-70{ }^{\circ} \mathrm{C}$ in $15 \%(\mathrm{v} / \mathrm{v})$ glycerol. All the strains belong to serotype $\mathrm{O} 1$, except for $V$. anguillarum M93Sm (and derivatives) which is serotype O2. Before use, bacteria were recovered initially onto appropriate agar, incubated at $22{ }^{\circ} \mathrm{C}$ for $48 \mathrm{~h}$, and then single colonies inoculated into broth (Table 1). Cultures were incubated $\left(22^{\circ} \mathrm{C} ; 150 \mathrm{rpm}\right.$; approximately $\left.12 \mathrm{~h}\right)$ until mid- to lateexponential phase and then bacterial cells were harvested by centrifugation $\left(2700 \times \mathrm{g} ; 15 \mathrm{~min} ; 4^{\circ} \mathrm{C}\right)$. The cell pellet was washed by resuspension in PBS, centrifuged as before, resuspended again in PBS, and then cell density determined by measuring absorbance at $600 \mathrm{~nm}\left(\mathrm{~A}_{600}\right)$. Bacterial suspensions were diluted with PBS to the desired CFU/mL, and all inocula were serially diluted in PBS in quadruplicate and plated on TSA or LB agar. Vib1 $(=6018 / 1=$ ATCC 43305 $)$ is available in reference culture collections and additional experimental data is provided for this strain as a means to facilitate interlaboratory comparisons.

\section{Insects}

G. mellonella larvae in their final instar stage were purchased (approximately $220 \mathrm{mg}$ each; UK Waxworms Ltd, Sheffield, UK), stored in the dark at $4{ }^{\circ} \mathrm{C}$, and used within 14 days. Unless otherwise stated, all experiments used groups containing 10 larvae, and most experiments were repeated using larvae from different batches to give $n=20$. A $50-\mu \mathrm{L}$ Hamilton syringe (Sigma-Aldrich Ltd) was used to inject larvae into the last left proleg with $10 \mu \mathrm{L}$ of bacterial suspension, antibiotic solution, or PBS. The syringe was cleaned between experiments with consecutive washes of $1 \%(\mathrm{w} / \mathrm{v})$ sodium hypochlorite, $70 \%$ ethanol and sterile water. Two negative control groups were always prepared: one group that underwent no manipulation to control for background larval mortality 
Table 1 Vibrio anguillarum isolates and strains used in this study

\begin{tabular}{|c|c|c|c|}
\hline Isolate/strain ${ }^{a}$ & Genotype & Culture medium $^{b}$ & Reference \\
\hline DM16 & $\begin{array}{l}\text { NB10 derivative carrying an in-frame } \\
3^{\prime} \text {-end deletion in flaA }\end{array}$ & $\mathrm{TSB} / \mathrm{TSA}+1.5 \% \mathrm{NaCl}$ & [27] \\
\hline$J R 1$ & $\begin{array}{l}\mathrm{STR}^{\mathrm{r}}, \mathrm{CHL}^{\mathrm{r}} \mathrm{M} 93 \mathrm{Sm} \text { derivative carrying } \\
\text { an inactivating insertion in vah1 }\end{array}$ & $\mathrm{LB}$ agar/broth $+1 \% \mathrm{NaCl}$ & {$[28]$} \\
\hline KD12 & $\begin{array}{l}\text { NB10 derivative carrying an in-frame } \\
5^{\prime} \text {-end deletion in flaD }\end{array}$ & $\mathrm{TSB} / \mathrm{TSA}+1.5 \% \mathrm{NaCl}$ & [29] \\
\hline KD27 & $\begin{array}{l}\text { NB10 derivative carrying an in-frame } \\
5^{\prime} \text {-end deletion in flaE }\end{array}$ & $\mathrm{TSB} / \mathrm{TSA}+1.5 \% \mathrm{NaCl}$ & [29] \\
\hline M93Sm & $\begin{array}{l}\text { Plasmid deficient; spontaneous STR } \\
\text { mutant of wild type M93 isolated } \\
\text { from Plecoglossus altivelis }\end{array}$ & LB agar/broth $+1 \% \mathrm{NaCl}$ & [41] \\
\hline NB10 & Wild type & $\mathrm{TSB} / \mathrm{TSA}+1.5 \% \mathrm{NaCl}$ & [42] \\
\hline NB10 cured & NB10 cured of pJM1 virulence plasmid & $\mathrm{TSB} / \mathrm{TSA}+1.5 \% \mathrm{NaCl}$ & {$[32]$} \\
\hline NB12 & $\begin{array}{l}\mathrm{CHL}^{r} \text { NB10 derivative carrying a } \\
\text { inactivating insertion in empA }\end{array}$ & $\mathrm{TSB} / \mathrm{TSA}+1.5 \% \mathrm{NaCl}$ & {$[30]$} \\
\hline S123 & $\begin{array}{l}\mathrm{STR}^{r}, \mathrm{CHL}^{\mathrm{r}} \mathrm{M} 93 \mathrm{Sm} \text { derivative carrying } \\
\text { a inactivating insertion in rtxA }\end{array}$ & $\mathrm{LB}$ agar/broth $+1 \% \mathrm{NaCl}$ & [7] \\
\hline S183 & $\begin{array}{l}\mathrm{STR}^{r}, \mathrm{CHL}^{r}, \mathrm{KAN}^{r} \mathrm{M} 93 \mathrm{Sm} \text { derivative } \\
\text { double mutant carrying an inactivating } \\
\text { insertions in } r t \times A \text { and in-frame deletion } \\
\text { in vah1 }\end{array}$ & $\mathrm{LB}$ agar/broth $+1 \% \mathrm{NaCl}$ & [7] \\
\hline Vib1 (=6018/1 = ATCC 43305) & Wild type & $\mathrm{TSB} / \mathrm{TSA}+1.5 \% \mathrm{NaCl}$ & [21] \\
\hline $\operatorname{Vib39}(=178 / 90)$ & Wild type & $\mathrm{TSB} / \mathrm{TSA}+1.5 \% \mathrm{NaCl}$ & [21] \\
\hline $\operatorname{Vib44}(=261 / 91)$ & Wild type & $\mathrm{TSB} / \mathrm{TSA}+1.5 \% \mathrm{NaCl}$ & [21] \\
\hline $\operatorname{Vib56}(=601 / 91)$ & Wild type & $\mathrm{TSB} / \mathrm{TSA}+1.5 \% \mathrm{NaCl}$ & [21] \\
\hline Vib64 (= A023) & Wild type & $\mathrm{TSB} / \mathrm{TSA}+1.5 \% \mathrm{NaCl}$ & [21] \\
\hline Vib79 (=LMG 12101) & Wild type & $\mathrm{TSB} / \mathrm{TSA}+1.5 \% \mathrm{NaCl}$ & [21] \\
\hline Vib85 (= 87-9-117) & Wild type & $\mathrm{TSB} / \mathrm{TSA}+1.5 \% \mathrm{NaCl}$ & [21] \\
\hline Vib87 (=T265) & Wild type & $\mathrm{TSB} / \mathrm{TSA}+1.5 \% \mathrm{NaCl}$ & [21] \\
\hline Vib88 (= 51/82/2) & Wild type & $\mathrm{TSB} / \mathrm{TSA}+1.5 \% \mathrm{NaCl}$ & [21] \\
\hline Vib93 (= 850610-1/6a) & Wild type & $\mathrm{TSB} / \mathrm{TSA}+1.5 \% \mathrm{NaCl}$ & [21] \\
\hline Vib134 (=91-8-178) & Wild type & $\mathrm{TSB} / \mathrm{TSA}+1.5 \% \mathrm{NaCl}$ & [21] \\
\hline
\end{tabular}

TSA, tryptone soya agar; TSB, tryptone soya broth; $\mathrm{CHL}^{r}$, chloramphicol-resistant; $\mathrm{KAN}^{r}$, kanamycin-resistant; STR ${ }^{\mathrm{r}}$, streptomycin-resistant

${ }^{a}$ Strain numbers in brackets refer to the nomenclature used by Pedersen et al. [25]

${ }^{\mathrm{b}} \mathrm{CHL}, \mathrm{KAN}$ and STR were added to the medium at the concentrations described in the Materials and Methods for reviving cryopreserved bacteria and preparing inocula for injection

(no manipulation control) and one group (uninfected control) that was injected with PBS only to control for the impact of physical trauma. There was never more than one death per control group per experiment. Larvae were stored in Petri dishes in the dark at $15{ }^{\circ} \mathrm{C}$ for up to $120 \mathrm{~h}$ and inspected every $24 \mathrm{~h}$ so that percentage survival could be calculated for each group; larvae were considered dead if they did not move after being touched with a sterile inoculation loop.

\section{Virulence of $V$. anguillarum in G. mellonella}

The relative virulence of 11 wild-type $V$. anguillarum strains that had been assessed for virulence in an earlier Salmo salar infection trial [25] was assessed in the insect model by inoculating with $10 \mu \mathrm{L}$ of suspensions containing $1 \times 10^{3}, 1 \times 10^{5}$ and $1 \times 10^{7}$ total CFU. Relative virulence in the insect was calculated as the cumulative area under the Kaplan-Meier plots of the $1 \times 10^{3}$, $1 \times 10^{5}$ and $1 \times 10^{7} \mathrm{CFU}$ groups, and this approach was sufficient to discriminate the virulence of each isolate. Then, relative virulence in the insect model was correlated against the $50 \%$ lethal dose values $\left(\mathrm{LD}_{50}\right)$ determined in the $S$. salar model by Pedersen et al. [25]. The virulence of the wild-type $V$. anguillarum strains was assessed in $G$. mellonella at $15{ }^{\circ} \mathrm{C}$ because the earlier $S$. salar trials were performed at this temperature, thus mitigating the effects of differential expression of temperature-regulated bacterial virulence factors. To examine the effect of culture filtrates on larval survival, culture supernatant was passed through a sterile polyethersulfone $0.22 \mu \mathrm{m}$ filter (Millipore, Watford, 
Herts, UK) and then injected into the larvae as above. Meanwhile, to examine the effects of heat-killed bacteria on larval survival, washed bacterial suspensions were adjusted to $5 \times 10^{9} \mathrm{CFU} / \mathrm{mL}$ with $\mathrm{PBS}$ and heat-killed $\left(60{ }^{\circ} \mathrm{C}\right.$; $25 \mathrm{~min}$ ). Heat killing was confirmed by the absence of colonies forming when $100 \mu \mathrm{L}$ of bacterial suspension was plated across TSA plates and incubation at $22{ }^{\circ} \mathrm{C}$ for $48 \mathrm{~h}$. Heat-killed bacterial suspension $(10 \mu \mathrm{L})$ was injected into the larvae as above. To confirm that antibiotic therapy could rescue larvae from $V$. anguillarum infection, larvae were inoculated with $1 \times 10^{5} \mathrm{CFU}$ and then treated at $2 \mathrm{~h}$, $24 \mathrm{~h}$ and $48 \mathrm{~h}$ with tetracycline (TET: $1 \mu \mathrm{g} / \mathrm{g}$ of larva) in $10 \mu \mathrm{L}$ PBS according to Desbois and Coote [20]. An additional control group assessed for the toxicity of the TET treatment. The 11 strains of $V$. anguillarum had MICs against TET of $0.0125-0.025 \mu \mathrm{g} / \mathrm{mL}$, which were determined according to Clinical and Laboratory Standards Institute Approved Standard M07-A8 (2008), except that the assays were performed at $22{ }^{\circ} \mathrm{C}$ in $\mathrm{NaCl}$-supplemented MHB (Table 1).

\section{V. anguillarum burden in G. mellonella tissues}

To assess bacterial burden in larvae infected with the 11 wild-type $V$. anguillarum strains, larvae were injected with $1 \times 10^{5}$ CFU. At 2 h, 4 h, 8 h, 24 h, 48 h, 72 h, 96, h and $120 \mathrm{~h}$, four surviving larvae in each group were selected at random for bacterial load determination. The last abdominal segment of each larva was removed with sterile scissors and the haemolymph (approximately 5-20 $\mu \mathrm{L}$ ) was harvested. Of this, $5 \mu \mathrm{L}$ was serially diluted in PBS and plated on TSA + PEN. Importantly, a preliminary investigation of $V$. anguillarum Vib79 had determined that approximately $95 \%$ of bacteria were found in the haemolymph rather than body tissues. In addition to sampling surviving larvae, dead larvae inoculated with Vib1, Vib44, Vib56 and Vib85 were bled and plated at $48 \mathrm{~h}$, while larvae inoculated with Vib93, Vib88 and Vib64 were sampled at $96 \mathrm{~h}, 120 \mathrm{~h}$ and $120 \mathrm{~h}$, respectively (all these larvae were alive at the time point $24 \mathrm{~h}$ previous). Groups of unmanipulated larvae and larvae inoculated with PBS only were included as controls. PEN in the agar had no effect on the recovery of $V$. anguillarum but prevented the growth of most contaminating microbes introduced from the larva surface or gut, and any that did form colonies were obvious and did not affect CFU determinations. Even so, a selection of recovered colonies from larvae infected with each strain were confirmed as $V$. anguillarum by: i) plating on thiosulfate-citratebile salts-sucrose (TCBS) agar as the formation of yellow colonies are characteristic of Vibrio spp. $\left(22^{\circ} \mathrm{C}\right.$; $72 \mathrm{~h}$ ); ii) positive reaction to the MONO-AQUA agglutination test (Bionor, Skien, Norway), which is specific for $V$. anguillarum; iii) positive amplification by polymerase chain reaction (PCR) of rpoN that encodes sigma factor $\sigma 54$ using forward primer rpoNang5' (5'-gttcatagcatcaatgaggag -3'; [26]) and reverse primer rpoN2SMR (5'-tgccgagcagatcaatatgt-3'). For PCR, single colonies were cultured and the cells collected as above. The cell pellet was suspended in $1 \mathrm{~mL}$ of sodium chloride-Tris-EDTA buffer and centrifuged $(13,000 \times \mathrm{g} ; 60 \mathrm{~s}$; room temperature). The supernatant was removed and the pellet suspended in $100 \mu \mathrm{L}$ TrisEDTA buffer, heated $\left(95^{\circ} \mathrm{C}\right.$ for $\left.10 \mathrm{~min}\right)$, and centrifuged $(13,000 \times \mathrm{g} ; 60 \mathrm{~s}$; room temperature). The supernatant was collected and DNA quantity and purity was assessed on a NanoDrop spectrophotometer (Thermo Scientific, Wilmington, DE, USA), before freezing at $-18{ }^{\circ} \mathrm{C}$ until needed. Each $10-\mu \mathrm{L}$ PCR reaction contained $5 \mu \mathrm{L}$ of $2 \mathrm{X}$ MyTaq mix (Bioline, London, UK), $0.4 \mu \mathrm{L}$ of each primer at $10 \mathrm{mM}, 1 \mu \mathrm{L}$ of DNA sample at $50 \mathrm{ng} / \mu \mathrm{L}$, and $3.2 \mu \mathrm{L}$ water. PCR reactions were run on a Biometra T Professional thermocycler (Goettingen, Germany) at: $95{ }^{\circ} \mathrm{C}$ for $1 \mathrm{~min}$; then 30 cycles of $95^{\circ} \mathrm{C}$ for $15 \mathrm{~s}, 62{ }^{\circ} \mathrm{C}$ for $15 \mathrm{~s}$ and $72{ }^{\circ} \mathrm{C}$ for $20 \mathrm{~s}$; and $72{ }^{\circ} \mathrm{C}$ for $2 \mathrm{~min}$. A no template control and a reaction containing DNA extracted from Vibrio ordalii Vib307 were performed as negative controls. PCR products were run on a $1 \%$ agarose gel containing $0.1 \mu \mathrm{g} / \mathrm{mL}$ ethidium bromide in $0.5 \%$ Tris-acetateEDTA buffer at $80 \mathrm{~V}$. Each well contained $2 \mu \mathrm{L}$ of sample, $1 \mu \mathrm{L} 6 \mathrm{X}$ loading dye (Thermo Scientific, Loughborough, UK) and $3 \mu \mathrm{L}$ of water.

\section{Virulence of $V$. anguillarum knockout mutants}

To assess the importance of various virulence factors known to play a role in infection of native hosts, the virulence of isogenic mutant and parent strains were assessed by injecting groups of larvae with $1 \times 10^{5} \mathrm{CFU}$ and comparing survival in each group. Mutant inocula were cultured in medium containing appropriate concentrations of antibiotics (see above and Table 2). Each pair of parent and knockout mutant had been tested for virulence differences in fish models previously [7, 27-30]. All virulence gene knockouts were located on the bacterial chromosomes. Bacteria were recovered from haemolymph and confirmed as $V$. anguillarum as above. Then the mutant genotypes of a selection of recovered colonies were confirmed by various means as follows. DNA was extracted from in vitro cultures and the colonies recovered from the larvae. Specific fragments in these samples were amplified by PCR and run on $1 \%$ agarose gels as above, except that annealing temperatures were altered according to primers used (Additional file 1: Table S1). To test for presence of the PJM1 virulence plasmid, two specific primer pairs were designed against two genes known to be located only on plasmid, $a n g R$ and fatE. The detection of PCR products of the two expected sizes confirmed the 
Table 2 Comparison of virulence of Vibrio anguillarum parent and isogenic mutant strains lacking virulence factors in Galleria mellonella larva and fish models of infection

\begin{tabular}{|c|c|c|c|c|c|c|}
\hline Knockout mutant & Parent & Inactivated/missing gene(s) & Gene function & $\begin{array}{l}\text { Virulence change of } \\
\text { mutant in fish }\end{array}$ & $\begin{array}{l}\text { Virulence change of } \\
\text { mutant in larvae }\end{array}$ & Reference \\
\hline NB10 cured & NB10 & Virulence plasmid (pJM1) & Iron-scavenging function & Not done & $\downarrow$ & [32] \\
\hline NB12 & NB10 & empA & Metalloprotease & $\downarrow$ (Oncorhynchus mykiss) & $\uparrow$ & {$[30]$} \\
\hline DM16 & NB10 & flaA & Flagellin protein & $\downarrow$ (O. mykiss) & $\uparrow$ & [27] \\
\hline KD12 & NB10 & flaD & Flagellin protein & $\downarrow$ (O. mykiss) & n.s. & [29] \\
\hline KD27 & NB10 & flaE & Flagellin protein & $\downarrow$ (O. mykiss) & $\uparrow$ & [29] \\
\hline S123 & M93Sm & $r t \times A$ & Repeat-in-toxin secreted toxin & $\downarrow$ (Salmo salar) & $\downarrow$ & [7] \\
\hline$J R 1$ & M93Sm & vah1 & Secreted haemolysin & $\downarrow$ (S. salar $)$ & n.s. & [28] \\
\hline S183 & M93Sm & rtxA and vah1 & Secreted toxin and haemolysin & $\downarrow$ (S. salar) & $\downarrow$ & [7] \\
\hline
\end{tabular}

$\uparrow$, virulence of mutant greater than parent; $\downarrow$ virulence of mutant less than parent. In the larva model, the virulence change of the mutant compared to the parent was either not significant (n.s.) or significant ( $p<0.05$; Holm's corrected). $n=20$

presence of the plasmid (Additional file 1: Table S1). For mutants created by plasmid insertion into the chromosome, primer pairs were designed against: i) a region of the plasmid $\sim 80-170$ bp up- or downstream from the insertion site; and ii) a region of the disrupted gene $\sim 25-$ 105 bp up- or downstream from the insertion site. The detection of a PCR product of the expected size confirmed the presence of the mutation (Additional file 1: Table S1). For mutants created by allelic exchange and in-frame deletion, primer pairs were designed against regions up- and downstream of the affected sites. Thus, parent and mutant strains would be expected to generate fragments of different lengths: mutant KD27 yielded a 589-bp product compared to a 779-bp product from the NB10 parent; DM16 yielded a 735-bp product compared to a 888-bp product from the NB10 parent; KD12 yielded a 419-bp product compared to a 599-bp product from the NB10 parent; and S183 yielded a 2534-bp product compared to a 2789-bp product from the M93Sm parent. Negative control strains were used in each assay to control for non-specific reactions.

\section{Statistical analyses}

Statistical tests were performed using SPSS v17.0 for Windows (SPSS Inc., Chicago, IL, USA). Larval survival was plotted according to the Kaplan-Meier method. Where desired, survival differences between groups of larvae were compared for significance with the logrank test. $p<0.05$ was considered to indicate a significant difference between groups and multiple comparisons were accounted for by applying Holm's correction [31]. Pearson's correlation coefficient was determined for virulence of the 11 wild-type $V$. anguillarum isolates in $S$. salar and $G$. mellonella models of infection.

\section{Results}

V. anguillarum establishes an infection in G. mellonella To assess whether G. mellonella would be a suitable model for assessing virulence of $V$. anguillarum, it was necessary to confirm that this bacterium established an infection in the insect. Initial challenge experiments with 11 wild-type isolates demonstrated that there was dosedependent killing of the larvae for each strain, meaning that greater inocula caused faster and greater mortality in groups (Fig. 1). Injection of larval groups with $5 \times 10^{7}$ CFU heat-killed bacteria had no significant effect on survival during $120 \mathrm{~h}$ and typically showed fewer deaths than groups challenged with the lowest dose of live bacteria $\left(1 \times 10^{3} \mathrm{CFU}\right)$, suggesting that larval deaths were not occurring due to toxicity of bacterial cells, and viable bacteria were required to cause mortal events (Fig. 1). Moreover, sterile culture filtrate from each isolate had no significant effect on larval survival, indicating that toxic extracellular metabolites were not being produced in vitro at sufficiently high concentrations to kill the larvae and viable bacteria were required to bring about death (Fig. 1). For all strains, treatment of infected larvae with $1 \mu \mathrm{g} / \mathrm{g}$ TET gave a significant increase in survival compared to infected larvae treated with PBS only, thus showing that larvae could be rescued from infection with an antibiotic that inhibited the growth of the bacterium (Fig. 2). TET treatment of uninfected larvae had no significant effect on larval survival (Fig. 2). Furthermore, each isolate of $V$. anguillarum showed replication inside the larvae and a group of seven isolates reached $\sim 1 \times 10^{9}$ $\mathrm{CFU} / \mathrm{mL}$ in haemolymph at $48 \mathrm{~h}$ while the remaining four isolates largely plateaued at $5 \times 10^{7} \mathrm{CFU} / \mathrm{mL}$ from $24 \mathrm{~h}$ (Fig. 3). Taken together, this evidence suggests that viable and replicating $V$. anguillarum cells are needed to establish a systemic infection of $G$. mellonella, and therefore it was next important to see whether virulence of $V$. anguillarum isolates correlated in fish and larva models.

Positive correlation in virulence of $V$. anguillarum isolates in S. salar and G. mellonella infection models

The relative virulence of each isolate in the larva was compared with virulence determined previously for each 

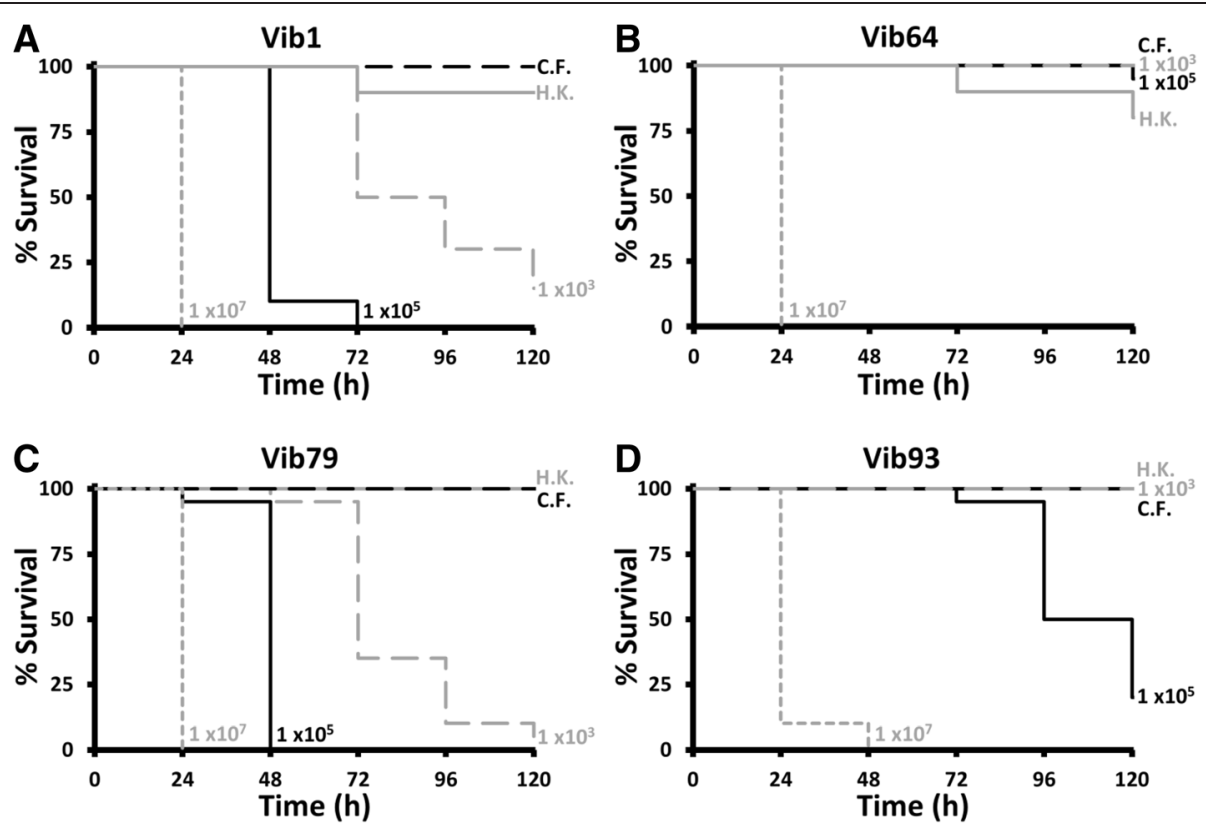

Fig. 1 Survival of groups of Galleria mellonella larvae injected with culture filtrate (C.F.); $1 \times 10^{3}, 1 \times 10^{5}$ and $1 \times 10^{7}$ total viable CFU; and $5 \times 10^{7}$ heatkilled (H.K.) CFU of four representative wild-type Vibrio anguillarum isolates with different virulence during 120 h, namely Vib1 (a), Vib64 (b), Vib79 (c) and Vib93 (d). For clarity, the unmanipulated and uninfected control groups data are not shown. $n=20$, except H.K. group where $n=10$

isolate in a $S$. salar infection model [25]. Interestingly, there was highly significant positive correlation $(p<0.01)$ between relative virulence of the 11 wild-type isolates in larva and fish models of infection, indicating that more virulent $V$. anguillarum strains in $S$. salar were also more virulent in the insect (Fig. 4). Closer examination of the growth of each isolate in the larva revealed that more virulent strains replicated faster and reached greater burden in the haemolymph than less virulent isolates (Fig. 3). Indeed, within $48 \mathrm{~h}$ the more virulent
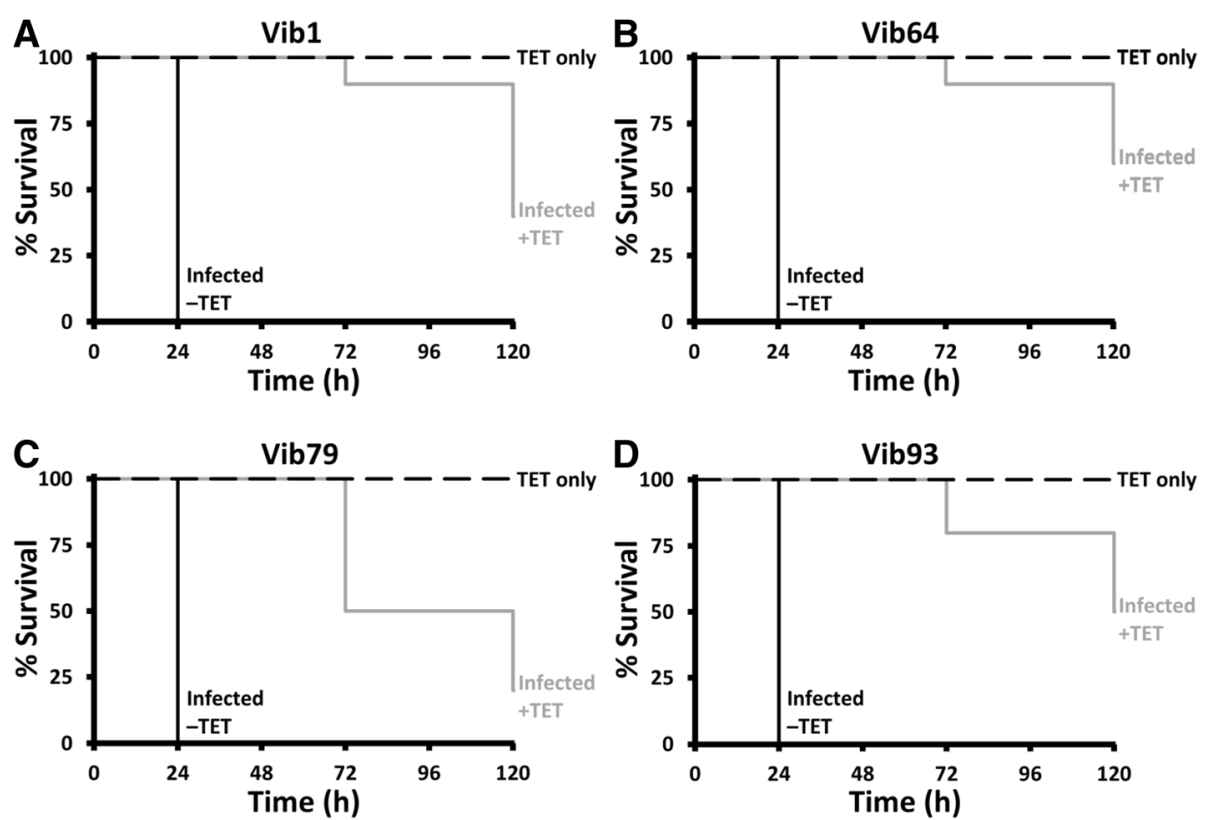

Fig. 2 Survival of Galleria mellonella larvae injected with $1 \times 10^{5}$ CFU of four representative wild-type Vibrio anguillarum isolates and treated at $2 \mathrm{~h}, 24 \mathrm{~h}$ and $48 \mathrm{~h}$ with tetracycline $(1 \mathrm{\mu g} / \mathrm{g}$ of larva; Infected + TET) in $10 \mu \mathrm{L}$ phosphate-buffered saline (PBS) during 120 h: Vib1 (a), Vib64 (b), Vib79 (c) and Vib93 (d). The infected control group was treated with PBS only (Infected -TET), while the TET only group controlled for the toxicity of the treatments. For clarity, the unmanipulated and uninfected control groups data are not shown. $n=10$ 


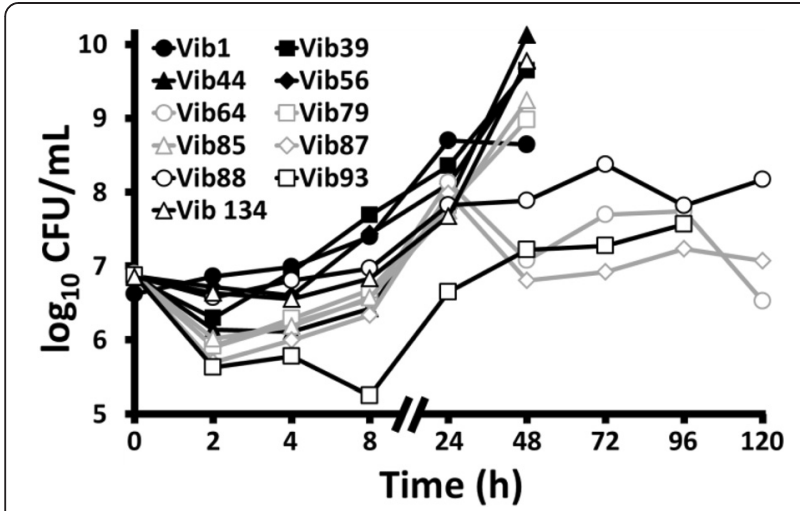

Fig. 3 Replication of 11 wild-type Vibrio anguillarum isolates in the haemolymph of Galleria mellonella larvae during $120 \mathrm{~h}$ after injection at $0 \mathrm{~h}$ with $1 \times 10^{5} \mathrm{CFU}$. Please note that the $\mathrm{CFU} / \mathrm{mL}$ value at $0 \mathrm{~h}$ refers to the PBS inoculum whereas at the other sampling times the $\mathrm{CFU} / \mathrm{mL}$ value refers to the haemolymph. It was not possible to obtain data for all strains at each sampling time after $48 \mathrm{~h}$ because most larvae were already dead and so were not sampled. For comparative purposes, the geometric mean (and standard error) of $\mathrm{CFU} / \mathrm{mL}$ in haemolymph for Vib1 at $2 \mathrm{~h}, 4 \mathrm{~h}, 8 \mathrm{~h}, 24 \mathrm{~h}$ and $48 \mathrm{~h}$ was $6.86(0.10), 6.99(0.07), 7.40(0.17), 8.70(0.15)$ and $8.64(0.85)$, respectively. For clarity, the unmanipulated and uninfected control groups data are not shown. Data points indicate geometric mean; error bars have not be added. $n=4$

isolates had increased to approximately $10^{9}-10^{10} \mathrm{CFU} /$ $\mathrm{mL}$ in the larval haemolymph, whereas less virulent strains reached approximately $10^{7}-10^{8} \mathrm{CFU} / \mathrm{mL}$ by this time (Fig. 3). After $48 \mathrm{~h}$ it was not possible to obtain data for the more virulent strains as most larvae were dead, while the haemolymph burden of less virulent strains remained at approximately $10^{7}-10^{8} \mathrm{CFU} / \mathrm{mL}$ for the duration of the experiment (Fig. 3). Additionally,

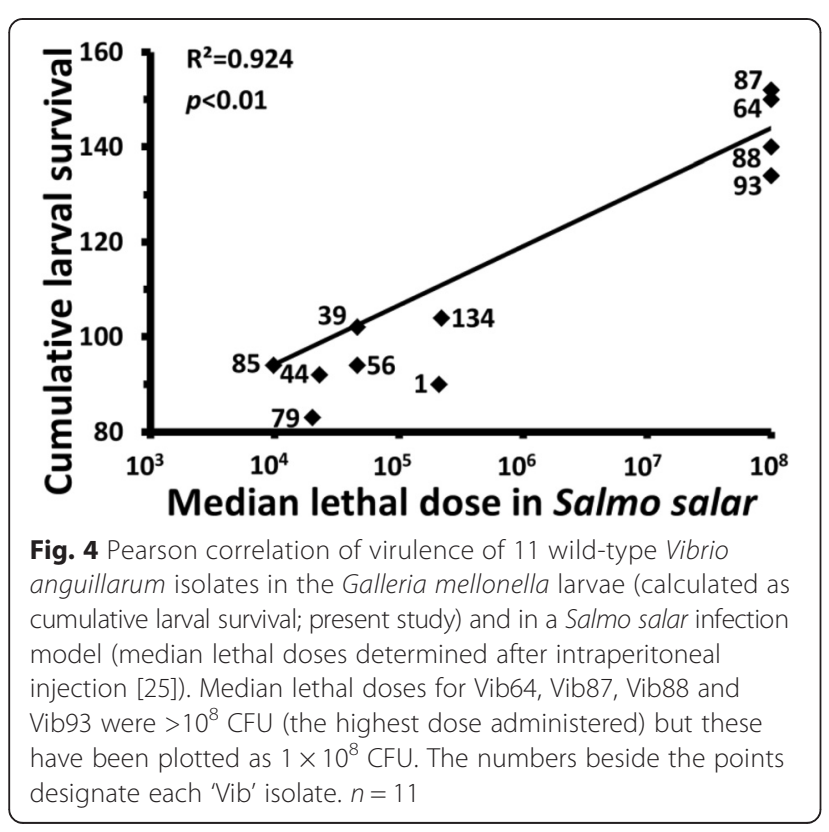

mean bacterial burden in the haemolymph of dead larvae was determined and there was always greater than $5.72 \times 10^{9} \mathrm{CFU} / \mathrm{mL}$ in these insects for the seven strains and times examined, indicating the likely breaching of a burden threshold before larval death ensued (data not shown).

\section{V. anguillarum virulence factors important in fish and $G$. mellonella infections}

To assess the role of various $V$. anguillarum virulence factors known to be important in fish infections, the virulence of pairs of parent strains and isogenic knockout mutant strains were compared in the larva model. First, the virulence of $V$. anguillarum NB10 was compared to a strain that had been cured of its PJM1 virulence plasmid, which codes for proteins that scavenge iron and plays a crucial role in virulence of fish infections [32, 33] (Table 2). As expected, the strain cured of its virulence plasmid was significantly less virulent in the larva compared with the parent isolate. In $S$. salar, strains lacking the $r t x A$ or vah1 toxin genes are less virulent than their respective parent isolates, and the reduced virulence of the $\Delta r t x A$ mutant was reflected in the larva model, though the $\Delta v a h 1$ mutant was equally as virulent as its parent (Table 2). A double-knockout strain lacking both $r t x A$ and vah1 genes had attenuated virulence in the larva model, which confirmed earlier observations in fish (Table 2). In fish, inactivation of eтpA (a metalloproteinase possibly important for tissue invasion) reduces virulence, but this same mutant was equally as virulent as its parent strain in the larva (Table 2). Finally, $V$. anguillarum strains lacking functional flaA, flaD, and flaE genes, which are necessary for flagella assembly and aid in adherence and colonisation of fish, show reduced virulence in fish, but these mutants did not show lower virulence in the larva compared with parent strains (Table 2).

\section{Discussion}

Alternative infection models are becoming more important as experimentation on vertebrates becomes increasingly regulated, but few alternative infection models are available to study pathogens of animals produced in aquaculture. Hence, this present study aimed to validate G. mellonella as an alternative model to investigate the virulence of $V$. anguillarum, a key aquaculture pathogen that infects many species and reduces farm productivity $[21,22,24]$.

In this present study, $V$. anguillarum was shown to establish systemic infections of G. mellonella larvae: the bacterium killed the larvae in a dose-dependent manner and replicated in vivo, while antibiotics rescued the insect from lethal bacterial inocula. The strains with greater virulence replicated to a greater extent inside the 
insect haemolymph to bring about faster larval mortality than less virulent isolates, presumably by more effectively combating the innate immune defences to exploit the host. Importantly, there was significant positive correlation between virulence of different wild-type $V$. anguillarum isolates in S. salar (native) and G. mellonella (alternative) infection models, which is key evidence when validating an alternative host for a particular pathogen, though this is rarely performed or achieved possibly due to the undesirable number of animals required [34, 35]. Pleasingly, the correlation in virulence of $V$. anguillarum isolates in $S$. salar and $G$. mellonella was demonstrated using published virulence data, meaning that no fish were required for this present study [25].

Our data showed that certain virulence determinants were similarly important during fish and insect infections, including the pJM1 virulence plasmid [33] and rtxA (a secreted toxin) [7]; however, some discrepancies were observed for the role of other virulence factors in the models, which is perhaps unsurprising given the physiological differences between the organisms. Indeed, some knockout strains were actually more virulent than parent, for example the $\triangle e m p A$ strain. However, Milton et al. [30] first demonstrated a role in virulence for empA in Oncorhynchus mykiss infection, but a subsequent study with an $\triangle e m p A$ mutant prepared from a different $V$. anguillarum isolate was unable to confirm a role in virulence for this protein in S. salar when bacteria were introduced by intraperitoneal injection [36]; a discrepancy that may be due to the use of different host species [36]. The $\triangle f l a A$ and $\triangle f l a E$ flagellum mutants were also more virulent than parent strains in the larva compared with fish. In $V$. anguillarum infections of fish, flagella act in host attachment and dissemination $[6,29]$ but, given the size of the larva and subversion of requirement for attachment thanks to direct injection into the haemolymph, these organelles may not be required for exploitation of the larva. Moreover, by knocking out flagellum protein genes, metabolic resources might be redirected to other virulence mechanisms that are more important during larva infection. The inability to evaluate the role of attachment and entry virulence factors, which are vital for infection [32], may at first seem to be a limitation of the G. mellonella model and indeed it is, however many studies in fish and aquatic invertebrates also rely solely on injected inocula through the external surface to establish infections [7, 25, 37-39]. An additional consideration that might explain the differences observed between fish and larva models is that various fish models were used to confirm the role of a virulence factor and thus comparison to the larva may be considered unfair as we do not know of the relative importance for these factors in different fish species (Table 2). In addition, a recent study of the mammalian pathogen Candida albicans in G. mellonella also found disparity for the importance of distinct virulence factors in different hosts [40]. These findings do not prevent G. mellonella from being useful in virulence studies of $V$. anguillarum, but it does mean that caution is required when extrapolating results or using this model to investigate a specific virulence factor. Therefore, additional work may be needed to identify which particular virulence traits can be studied in this model.

The increasing desire to reduce vertebrate experimentation and adhere to the principles of the 3Rs, while also reducing costs and infrastructure requirements, or other inconveniences associated with studying a pathogen in a native aquaculture host such as strict legislation, mean there are strong incentives for pursuing new more ethically acceptable alternative infection models [3, 4, 14]. Existing alternatives suffer from the need for tissue culture or aquarium facilities, and models may lack immune complexity or be unsuitable for studying certain virulence factors. The G. mellonella model is simple to perform, shares functional similarity to many of the innate immune responses of aquaculture species, and permits high-throughput experiments of pathogenicity and virulence factors [14-19]. In this present study, we have validated the G. mellonella model for just one aquaculture pathogen ( $V$. anguillarum), but this model is likely to be highly suited to the study of virulence in other fish and aquaculture pathogens. Still, the G. mellonella model requires full validation for each particular pathogen before its suitability for studying that microbe can be ensured. Crucially, the model does not rely on liquid systems, thus reducing infrastructure requirements and biohazard risks associated with large volumes of contaminated water, which is especially desirable if studying zoonotic pathogens.

\section{Conclusion}

Aquaculture is playing an increasingly important role in global food production and its long-term sustainability relies on the prevention and control of microbial infectious diseases through the development of new and improved treatments, vaccinations and management practices. The use of alternative models such as $G$. mellonella may rapidly improve our understanding of microbial pathogens in aquaculture and lead to the timely introduction of effective remedies for infectious diseases, while considerably reducing the number of vertebrates used in such studies.

\section{Availability of data and materials}

All materials described in this manuscript, including the raw data, are freely available to any scientist wishing to use them for non-commercial purposes and these can be obtained from the Corresponding Author by request. 


\section{Ethics statement}

This study was submitted to and approved by the Institute of Aquaculture ethics committee.

\section{Additional file}

Additional file 1: Table S1. Confirmation of mutant strain genotypes: Type of mutation in each strain, primers, expected amplicon length and PCR conditions.

\section{Competing interests}

The authors declare that they have no competing interests.

\section{Authors' contributions}

SM, DVJ, JW, BA and APD have contributed intellectually to this study and provided critical input into the manuscript. SM, DVJ, JW, BA and APD have approved the final version of this manuscript and share responsibility and accountability for the data reported and its interpretation. APD and SM designed the experiments, analysed the data and wrote the first draft of the manuscript. SM performed the experiments; APD conceived the study.

\section{Acknowledgements}

We wish to thank Dr Dawn Austin (Heriot Watt University, UK), Professor Debra Milton (Umea University, Sweden) and Professor David Nelson (University of Rhode Island, US) for kindly gifting the bacterial strains. This work was funded by a University of Stirling Collaborative Research Studentship in partnership with the Centre for Environment, Fisheries and Aquaculture Science (Weymouth, UK).

\section{Author details}

${ }^{1}$ Marine Biotechnology Research Group, Institute of Aquaculture, School of Natural Sciences, University of Stirling, Stirling, UK. ${ }^{2}$ Centre for Environment, Fisheries and Aquaculture Science, Weymouth, UK. ${ }^{3}$ Present address: Department of Environmental Science and Technology, Cranfield University, Bedford, UK.

Received: 23 March 2015 Accepted: 12 June 2015 Published online: 23 June 2015

\section{References}

1. Lafferty KD, Harvell CD, Conrad JM, Friedman CS, Kent ML, Kuris AM, Powel EN, Rondeau D, Saksida SM. Infectious diseases affect marine fisheries and aquaculture economics. Ann Rev Mar Sci. 2015;7:471-96.

2. Froquet R, Cherix N, Burr SE, Frey J, Vilches S, Tomas JM, Cosson P. Alternative host model to evaluate Aeromonas virulence. Appl Environ Microbiol. 2007;73:5657-9.

3. Zak O, Oreilly T. Animal models in the evaluation of antimicrobial agents Antimicrob Agents Chemother. 1991;35:1527-31.

4. Chamilos G, Lionakis MS, Lewis RE, Kontoyiannis DP. Role of mini-host models in the study of medically important fungi. Lancet Infect Dis. 2007;7:42-55.

5. Schaeck M, Van den Broeck W, Hermans K, Decostere A. Fish as research tools: Alternatives to in vivo experiments. Altern Lab Anim. 2013;41:219-29.

6. Ormonde P, Horstedt P, OToole R, Milton DL. Role of motility in adherence to and invasion of a fish cell line by Vibrio anguillarum. J Bacteriol. 2000;182:2326-8.

7. Li L, Rock JL, Nelson DR. Identification and characterization of a repeat-in-toxin gene cluster in Vibrio anguillarum. Infect Immun. 2008;76:2620-32

8. Mou XY, Spinard EJ, Driscoll MV, Zhao WJ, Nelson DR. H-NS Is a negative regulator of the two hemolysin/cytotoxin gene clusters in Vibrio anguillarum. Infect Immun. 2013:81:3566-76.

9. Brackman G, Celen S, Hillaert U, Van Calenbergh S, Cos P, Maes L, Nelis HJ, Coenye T. Structure-activity relationship of cinnamaldehyde analogs as inhibitors of Al-2 based quorum sensing and their effect on virulence of Vibrio spp. PLoS ONE. 2011;6, e16084.

10. Pang MD, Lin XQ, Hu M, Li J, Lu CP, Liu YJ. Tetrahymena: An alternative model host for evaluating virulence of Aeromonas strains. PLoS ONE. 2012;7, e48922.
11. Defoirdt $T$, Bossier $P$, Sorgeloos $P$, Verstraete $W$. The impact of mutations in the quorum sensing systems of Aeromonas hydrophila, Vibrio anguillarum and Vibrio harveyi on their virulence towards gnotobiotically cultured Artemia franciscana. Environ Microbiol. 2005;7:1239-47.

12. van Soest JJ, Stockhammer OW, Ordas A, Bloemberg GV, Spaink HP, Meijer $\mathrm{AH}$. Comparison of static immersion and intravenous injection systems for exposure of zebrafish embryos to the natural pathogen Edwardsiella tarda. BMC Immunol. 2011:12:58.

13. Harvie EA, Green JM, Neely MN, Huttenlocher A. Innate immune response to Streptococcus iniae infection in zebrafish larvae. Infect Immun. 2013;81:110-21.

14. Desbois AP, Coote PJ. Utility of greater wax moth larva (Galleria mellonella) for evaluating the toxicity and efficacy of new antimicrobial agents. Adv Appl Microbiol. 2012;78:25-53.

15. Magnadottir B. Innate immunity of fish (overview). Fish Shellfish Immunol. 2006:20:137-51.

16. Jiang H, Vilcinskas A, Kanost MR. Immunity in lepidopteran insects. In: Söderhäll K, editor. Invertebrate Immunity. Austin: Landes Bioscience and Springer Science + Business Media; 2010. p. 181-204.

17. Neumann NF, Stafford JL, Barreda D, Ainsworth AJ, Belosevic M. Antimicrobial mechanisms of fish phagocytes and their role in host defense. Dev Comp Immunol. 2001;25:807-25.

18. Cytrynska M, Mak P, Zdybicka-Barabas A, Suder P, Jakubowicz T. Purification and characterization of eight peptides from Galleria mellonella immune hemolymph. Peptides. 2007;28:533-46.

19. Agius C, Roberts RJ. Melano-macrophage centres and their role in fish pathology. J Fish Dis. 2003;26:499-509.

20. Desbois AP, Coote PJ. Wax moth larva (Galleria mellonella): an in vivo model for assessing the efficacy of antistaphylococcal agents. J Antimicrob Chemother. 2011;66:1785-90.

21. Austin B, Alsina M, Austin DA, Blanch AR, Grimont F, Grimont PAD, Jofre J, Koblavi S, Larsen JL, Pedersen K, Tiainen T, Verdonck L, Swings J. Identification and typing of Vibrio anquillarum - A comparison of different methods. Syst Appl Microbiol. 1995;18:285-302

22. Frans I, Michiels CW, Bossier P, Willems KA, Lievens B, Rediers H. Vibrio anguillarum as a fish pathogen: virulence factors, diagnosis and prevention. J Fish Dis. 2011:34:643-61.

23. Naka H, Crosa JH. Genetic determinants of virulence in the marine fish pathogen Vibrio anguillarum. Fish Pathol. 2011;46:1-10.

24. Paillard C, Le Roux F, Borrego JJ. Bacterial disease in marine bivalves, a review of recent studies: Trends and evolution. Aquat Living Resour. 2004;17:477-98

25. Pedersen K, Gram L, Austin DA, Austin B. Pathogenicity of Vibrio anguillarum serogroup $\mathrm{O} 1$ strains compared to plasmids, outer membrane protein profiles and siderophore production. J Appl Microbiol. 1997:82:365-71.

26. Gonzalez SF, Osorio CR, Santos Y. Development of a PCR-based method for the detection of Listonella anguillarum in fish tissues and blood samples. Dis Aquat Organ. 2003;55:109-15.

27. Milton DL, OToole R, Horstedt P, Wolf-Watz H. Flagellin A is essential for the virulence of Vibrio anguillarum. J Bacteriol. 1996;178:1310-9.

28. Rock JL, Nelson DR. Identification and characterization of a hemolysin gene cluster in Vibrio anguillarum. Infect Immun. 2006;74:2777-86.

29. McGee K, Horstedt P, Milton DL. Identification and characterization of additional flagellin genes from Vibrio anguillarum. J Bacteriol. 1996;178:5188-98.

30. Milton DL, Norqvist A, Wolf-Watz H. Cloning of a metalloprotease gene involved in the virulence mechanism of Vibrio anguillarum. J Bacteriol. 1992:174:7235-44.

31. Holm S. A simple sequentially rejective multiple test procedure. Scand J Statist. 1979:6:65-70

32. Weber B, Chen C, Milton DL. Colonization of fish skin is vital for Vibrio anquillarum to cause disease. Environ Microbiol Rep. 2010;2:133-9.

33. Crosa $\mathrm{JH}$, Hodges $\mathrm{LL}$, Schiewe $\mathrm{MH}$. Curing of a plasmid is correlated with an attenuation of virulence in the marine fish pathogen Vibrio anguillarum. Infect Immun. 1980;27:897-902.

34. Olsen RJ, Watkins ME, Cantu CC, Beres SB, Musser JM. Virulence of serotype M3 Group A Streptococcus strains in wax worms (Galleria mellonella larvae). Virulence. 2011:2:111-9.

35. Jander G, Rahme LG, Ausubel FM. Positive correlation between virulence of Pseudomonas aeruginosa mutants in mice and insects. J Bacteriol. 2000;182:3843-5. 
36. Denkin SM, Nelson DR. Regulation of Vibrio anguillarum empA metalloprotease expression and its role in virulence. Appl Environ Microbiol. 2004;70:4193-204.

37. Wang $Y$, Zhang XH, Austin B. Comparative analysis of the phenotypic characteristics of high- and low-virulent strains of Edwardsiella tarda. J Fish Dis. 2010;33:985-94.

38. Amparyup P, Charoensapsri W, Tassanakajon A. Two prophenoloxidases are important for the survival of Vibrio harveyi challenged shrimp Penaeus monodon. Dev Comp Immunol. 2009;33:247-56.

39. Huang WB, Ren HL, Gopalakrishnan S, Xu DD, Qiao K, Wang KJ. First molecular cloning of a molluscan caspase from variously colored abalone (Haliotis diversicolor) and gene expression analysis with bacterial challenge. Fish Shellfish Immunol. 2010:28:587-95.

40. Amorim-Vaz S, Delarze E, Ischer F, Sanglard D, Coste AT. Examining the virulence of Candida albicans transcription factor mutants using Galleria mellonella and mouse infection models. Front Microbiol. 2015;6:367.

41. Denkin SM, Nelson DR. Induction of protease activity in Vibrio anguillarum by gastrointestinal mucus. Appl Environ Microbiol. 1999;65:3555-60.

42. Norqvist A, Hagstrom A, Wolf-Watz H. Protection of rainbow trout against vibriosis and furunculosis by the use of attenuated strains of Vibrio anquillarum. Appl Environ Microbiol. 1989;55:1400-5.

\section{Submit your next manuscript to BioMed Central and take full advantage of:}

- Convenient online submission

- Thorough peer review

- No space constraints or color figure charges

- Immediate publication on acceptance

- Inclusion in PubMed, CAS, Scopus and Google Scholar

- Research which is freely available for redistribution 